\title{
La investigación aplicada en la Carrera de Ciencia y Producción Agropecuaria
}

\section{Miguel Vélez ${ }^{1}$}

La presente edición de la revista Ceiba contiene los resúmenes de las investigaciones realizadas en 2007 y 2008 en la Carrera de Ciencia y Producción Agropecuaria de la Escuela Agrícola Panamericana, Zamorano, Honduras. Las investigaciones fueron las tesis de los estudiantes dirigidas por los docentes de la Escuela Agrícola Panamericana y profesionales colaboradores de otras universidades o empresas. Las áreas y tipo de investigación demuestran el interés y compromiso con la misión de Zamorano de apoyar el desarrollo de la industria agropecuaria nacional e internacional para hacerla más productiva, eficiente en el uso de los recursos y más amigable con el ambiente.

En el área de producción vegetal las investigaciones incluyen el mapeo detallado de los suelos de la Escuela Agrícola Panamericana y propuestas para su manejo; la determinación de la absorción de nutrientes y de agua por cultivos como la caña y las flores en sus etapas de desarrollo, el efecto de diversas técnicas de conservación de suelos, el uso de biofertilizantes, el control químico y biológico de insectos y malezas, la identificación de los agentes causantes de la destrucción de más del 95\% de las palmas de coco en la Costa Atlántica de Honduras, la identificación de nuevos agentes biológicos capaces de controlar plagas y enfermedades, el mejoramiento genético del frijol y el desarrollo de técnicas para la micropropagación de cultivos.

En producción animal la investigación incluyó el uso de enzimas, levaduras, secuestrantes de micotoxinas y otros aditivos para mejorar el aprovechamiento de los alimentos y reducir la excreción de nutrientes en las heces, el uso de alimentos no convencionales como la caña en ganado lechero, nuevas técnicas de manejo de aves (diversas camas para el engorde), cerdos (engorde de verracos) y de peces (hormonas, jaulas en lagunas), manipulación de la reproducción mediante manejo y uso de hormonas en vacunos y cerdos, inducción de la lactancia en vaquillas y economía de diversos sistemas de producción de vacunos de leche y carne.

La Escuela Agrícola Panamericana, los profesores y estudiantes esperan que los resultados de las investigaciones de estas tesis sean útiles a la agricultura nacional e internacional de la región a la que sirve la Escuela Agrícola Panamericana. Las tesis completas están disponibles al público en la Biblioteca Wilson Popenoe de la Escuela Agrícola Panamericana.

\footnotetext{
${ }^{1}$ Director de la Carrera de Ciencia y Producción Agropecuaria, Escuela Agrícola Panamericana, Zamorano, Honduras.
} 